\title{
The mechanism of hypoxaemia after laparotomy
}

\author{
J . GEORG, I. HOR N UM, ANDK. MELLEMGAAR D \\ From the Medical Department B and Surgical Department C, Rigshospitalet, Copenhagen, Denmark
}

In 18 patients who were undergoing upper laparotomies the alveolo-arterial oxygen difference and right-to-left shunt were measured before the operation, on the first post-operative day, and in some cases also later in the post-operative period. The arterial oxygen tension was found to be considerably reduced post-operatively. The right-to-left shunt estimated by the hydrogen isotope technique was moderately increased in most instances, but the increase was far from large enough to account for the observed hypoxaemia. It is concluded that uneven distribution of ventilation relative to perfusion is the main cause of post-operative hypoxaemia, whereas veno-arterial shunt through atelectatic areas is of minor importance.

An abdominal operation, especially a high laparotomy, has a profound influence on the function of the lungs. Vital capacity is reduced to about half the pre-operative value, whereas the functional residual capacity decreases somewhat less. Respiratory minute volume remains fairly constant, but respiration becomes more frequent with a smaller tidal volume (Anscombe, 1957).

A fall in arterial oxygen saturation or oxygen tension after operation has been noted by many authors, even in patients without evidence of pulmonary complications (Troell, 1951 ; Carlsten, Norlander, and Troell, 1954 ; Gordh, Linderholm, and Norlander, 1958; Nunn and Payne, 1962; Conway and Payne, 1964). Arterial carbon dioxide tension, however, remains essentially unchanged (Linderholm and Norlander, 1958; Palmer and Gardiner, 1964). There is thus no evidence of alveolar hypoventilation, which would cause a raised arterial carbon dioxide tension. It seems likely that the post-operative hypoxaemia is due either to disturbances of the normal ventilation to perfusion relationships or to a right-toleft shunt through atelectatic parts of the lungs.

In the series of investigations to be reported we have tried to separate these two components as far as possible. This has been done with the use of two shunt estimations. The alveolo-arterial oxygen gradient during air breathing has been used to calculate the physiological shunt, i.e., the sum of contributions, whether from underventilated alveoli or from veno-arterial shunts, which cause a decrease in arterial oxygen tension.
Injection of the radioactive hydrogen isotope, tritium, has been used to calculate the pure right-to-left shunt, i.e., the amount of blood which passes from the venous to the arterial side without contact with alveolar gas.

\section{MATERIAL AND METHODS}

Eighteen patients (14 men and 4 women, age range 22-70 years) undergoing gastric or biliary tract operations were studied. All patients were in good general condition without fever, shock, or anaemia. None of them had a history of chronic or recurrent cough or dyspnoea, and pre-operative lung function studies, including determination of lung volumes, ventilatory capacity, and intrapulmonary gas mixing by the nitrogen washout technique showed normal results in each case.

The study included a pre-operative investigation and one or more investigations in the post-operative period, preferably beginning on the first post-operative day about 24 hours after the operation. In each case an indwelling needle was placed in a brachial artery and blood was drawn for determination of oxygen tension $\left(\mathrm{PaO}_{2}\right)$ with a polarographic method (Bartels, 1951), and $p \mathrm{H}$ and carbon dioxide tension $\left(\mathrm{PaCO}_{2}\right)$ with Astrup's interpolation method (Siggaard Andersen, Engel, J $\varnothing$ rgensen, and Astrup, 1960). An intravenous injection of tritium $\left({ }^{3} \mathrm{H}_{2},{ }^{\prime} \mathrm{T}_{2}\right.$ ') as a physical solution in isotonic saline was then given rapidly, and arterial blood was drawn from 5 to 30 seconds following the injection for determination of right-to-left shunt by the method of Lassen, Mellemgaard, and Georg (1961).

The alveolar oxygen tension $\left(\mathrm{PAO}_{2}\right)$ was calculated from the alveolar air equation using an assumed respiratory quotient of 0.8 . From $\mathrm{PAO}_{2}$ and $\mathrm{PaO}_{2}$ the 
alveolo-arterial oxygen tension difference $\left(\mathrm{P}(\mathrm{A}-\mathrm{a}) \mathrm{O}_{2}\right)$ was obtained. This alveolo-arterial oxygen difference was also expressed as the physiological shunt ( $\left.\mathbf{Q}_{\mathbf{8}}\right)$, i.e., the fractional perfusion through non-ventilated alveoli and 'anatomical' shunt, which would account for the entire observed $P(A-a) O_{2}$.

$\dot{Q}_{s}$ was calculated from the shunt equation

$$
\frac{\dot{Q}_{\mathrm{s}}}{\dot{\mathrm{Q}}}=\frac{\mathrm{C}_{(\mathrm{A}-\mathrm{a}) \mathrm{O}_{2}}}{\mathrm{C}_{(\mathrm{A}-\mathrm{a}) \mathrm{O}_{2}}+\mathrm{C}_{(\mathrm{a}-\overline{\mathrm{v}}) \mathrm{O}_{2}}}
$$

$\mathrm{C}(\mathrm{A}-\mathrm{a})_{2}$ is the alveolo-arterial oxygen difference expressed in concentration units ( $\mathrm{ml} . / \mathrm{l}$.). It is calculated from $\mathrm{PAO}_{2}, \mathrm{PaO}_{2}$, the oxygen capacity of the blood estimated from the haemoglobin concentration, the standard oxyhaemoglobin dissociation curve of Dill and Forbes (Severinghaus, 1958), and the solubility of $\mathrm{O}_{2}$ in blood (Sendroy, Dillon, and Van Slyke, 1934). The arteriovenous oxygen difference, $\mathrm{C}(\mathrm{a}-\overline{\mathrm{v}}) \mathbf{O}_{2}$, was not measured in the present study. An average value of $45 \mathrm{ml}$./1. was assumed.

Determination of right-to-left shunt ( $\left.\mathrm{Q}_{\mathrm{rl}}\right)$ with hydrogen (tritium) utilizes the very poor solubility of this gas in blood ( $\lambda$ blood/gas $=0.017$ (Mellemgaard, Lassen, and Georg, 1962)). As a consequence of this low solubility blood passing through pulmonary capillaries in contact with air-containing alveoli is almost completely cleared of the gas. The fraction of $T_{2}$ remaining in the arterial blood after the first passage through the central circulation is therefore a sensitive measure of the right-to-left shunt.

T A B L E

ARTERIAL CARBON DIOXIDE TENSION $\left(\mathrm{PaCO}_{2}\right)$, OXYGEN TENSION $\left(\mathrm{PaO}_{2}\right)$, CALCULATED ALVEOLO-ARTERIAL OXYGEN TENSION DIFFERENCE $\left(\mathrm{P}(\mathrm{A}-\mathrm{a}) \mathrm{O}_{2}\right)$, CALCULATED PHYSIOLOGICAL SHUNT $\left(\dot{\mathrm{Q}}_{\mathrm{g}}\right)$, AND RECOVERY OF TRITIUM $\left(\mathrm{RT}_{\mathfrak{z}}\right) \mathrm{WHICH}$ IS TAKEN AS A MEASURE OF RIGHT-TO-LEFT SHUNT

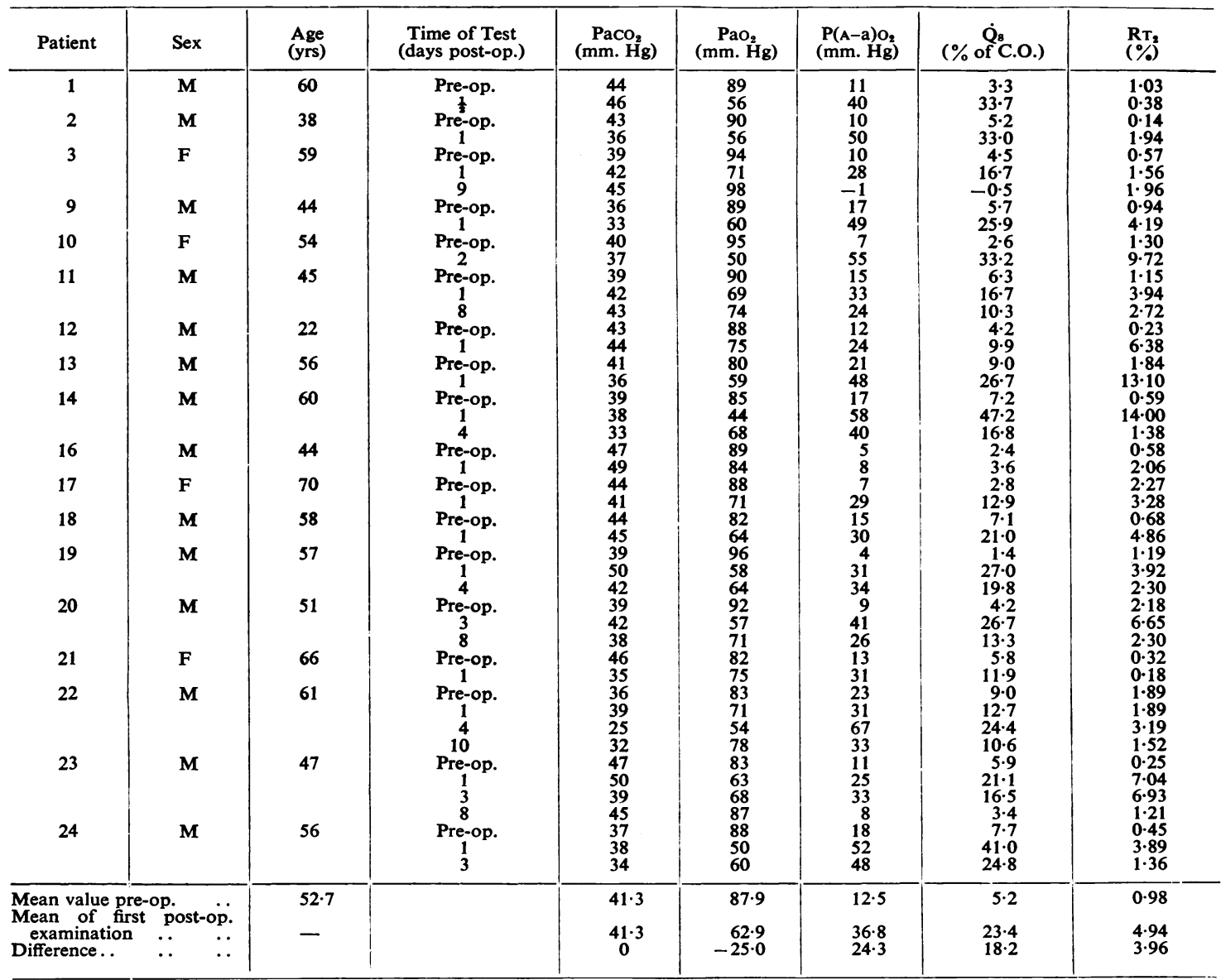

C.O. $=$ Cardiac output. 
This fraction (the 'recovery' of tritium, $R_{T_{2}}$ ) was calculated from the ratio of tritium concentration to the concentration of a non-volatile tracer (tritiated water, THO) relative to the corresponding ratio in the injectate. Tritium was analysed by the method of Robinson (1955) after conversion to tritiated water.

\section{RESULTS}

The Table gives the results of all preand post-operative investigations. The pre-operative gas tensions were within normal limits for the age of the subjects, and $\mathbf{R}_{\mathrm{T} 2}$ did not exceed the upper normal limit of $2.3 \%$ in any case (cf. Mellemgaard, 1966).

The characteristic finding in the first post-operative study was of a marked reduction of the arterial oxygen tension. Only in one case (case 16) was $\mathrm{PaO}_{2}$ not below the normal range. The changes in arterial carbon dioxide tension were only slight, and the average post-operative $\mathrm{PaCO}_{2}$ was identical with the pre-operative value, thus demonstrating that the hypoxaemia was not caused by hypoventilation. The post-operative $\mathbf{R}_{\mathrm{T} 2}$ was generally somewhat increased, the mean value being $4.74 \%$, as opposed to a pre-operative mean of $0.98 \%$. In 12 of the 18 cases the postoperative $\mathbf{R}_{\mathrm{T} 2}$ exceeded normal limits, the highest value being $14.0 \%$. However, as is apparent from Fig. 1, the $\mathbf{R}_{\mathrm{T} 2}$ was frequently unchanged or only slightly increased, and on repeated examinations during subsequent days $\mathbf{R}_{\mathrm{T} 2}$ tended toward normal even in cases where $\mathrm{PaO}_{2}$ was still considerably decreased.

The contribution of the right-to-left shunt to the observed alveolo-arterial oxygen difference was evaluated by comparing $\mathbf{R}_{\mathrm{T}_{2}}$ with the physiological shunt $\dot{\mathbf{Q}}_{\mathrm{s}}$. It will be seen from Fig. 2 that, even if the post-operative $\mathbf{R}_{T_{2}}$ was considerably increased, it accounted for only a small fraction of $\dot{Q}_{s}$.

Eight patients developed clinical signs of postoperative pulmonary complications: fever and râles, cough and expectoration, or positive radiographic findings. The mean $\mathbf{R}_{\mathrm{T}_{2}}$ and $\dot{Q}_{\mathrm{B}}$ of this group $(5.0 \%$ and $23.9 \%)$ was identical with the mean $\mathbf{R}_{\mathbf{T}_{2}}$ and $\dot{Q}_{\mathbf{s}}$ of the 10 clinically uncomplicated cases $(5 \cdot 0 \%$ and $24 \cdot 3 \%)$.
FIG. 2. Comparison of the average physiological and

right-to-left shunts before and one day after operation.

FIG. 1. Results of estimation of rightto-left shunt before and after operation. The ordinate gives the recovery of tritium $\left(R \mathbf{T}_{2}\right)$ which is nearly identical to the right-to-left shunt expressed as a percentage of the cardiac output.

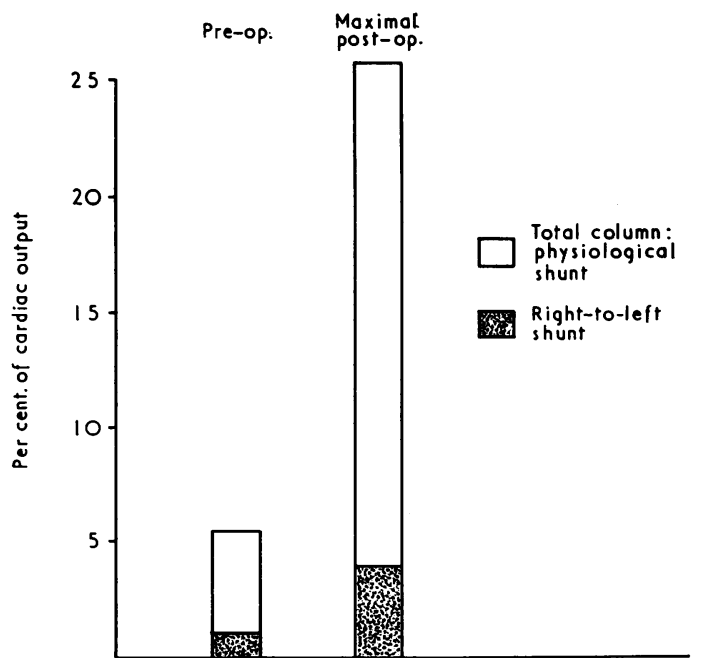




\section{DISCUSSION}

The results of post-operative pulmonary function studies lend some support to the hypothesis that the hypoxaemia observed after abdominal surgery is due to a right-to-left shunt through atelectatic parts of the lungs. A decrease in functional residual capacity was observed by Beecher (1933) and Brattström (1954). Gordh et al. (1958) found evidence of considerable veno-arterial shunting on the first post-operative day by measuring the alveolo-arterial oxygen tension difference after 15 minutes of oxygen breathing. The decrease in compliance observed by Bendixen, Hedley-Whyte, and Laver (1963) is also most readily explained by the development of atelectases, although it could result from a change of surface tension in open alveoli. The finding of a post-operative improvement in mixing efficiency of the lungs, as demonstrated with nitrogen (Brattström, 1954) or with helium technique (Ross, Eller, Ley, and King, 1963), is in accordance with this hypothesis, since alveolar collapse may be presumed to involve primarily regions with low ventilation/ perfusion ratios.

An argument against this concept has been the lack of correlation between arterial hypoxaemia and radiologically demonstrable atelectases. This may be explained, however, by the occurrence of multiple small atelectatic areas which cause oxygen desaturation without being visible on radiography. A more convincing counterargument is provided by the finding of Conway and Payne (1963) and Poulsen (1965) that even a moderate increase in the oxygen concentration of the inspired air, e.g., to $30 \%$, may abolish the arterial hypoxaemia. If the desaturation were due solely to a veno-arterial shunt, a slight increase in alveolar oxygen tension would have little effect on the arterial hypoxaemia.

The results of the present study are in accordance with the latter view, since we have found the main cause of the hypoxaemia to be ventilation/perfusion inequalities with relative overperfusion of underventilated areas. A venoarterial shunt-probably through atelectatic areas -contributes to the hypoxaemia but is of minor importance.

The validity of this conclusion is dependent on the difference between the right-to-left shunt and the physiological shunt. Both estimations may be subject to error. The use of an assumed arteriovenous oxygen difference gives rise to some uncertainty in the calculation of the physiological shunt. The oxygen difference may well be considerably greater post-operatively than pre- operatively on account of an increase in oxygen uptake in the presence of unaltered or decreased cardiac output. Even if the actual arteriovenous oxygen difference were considerably greater than assumed, say 60 instead of $45 \mathrm{ml}$./l., the calculated post-operative physiological shunt would still be large compared to the right-to-left shunt observed.

Another objection is that the estimated rightto-left shunt does not account for all veno-arterial shunting. The tritium method measures only that fraction of the labelled mixed venous blood which bypasses the alveoli, whereas contributions from other sources (bronchial and thebesian venous flow to the left side of the heart) are not measured. It is a reasonable assumption, however, that these contributions are of the same magnitude as in normal subjects, i.e., about $2 \%$ of the cardiac output (Mellemgaard, 1966), and not affected by the operative procedure. The pure right-to-left shunt is thus the relevant measurement in this connexion, and the conclusion that veno-arterial shunting is of minor importance for the post-operative hypoxaemia should rest on solid ground.

Our findings are not incompatible with the existence of widespread atelectases, which the results of pulmonary function tests mentioned above would suggest, but they indicate that if such collapsed areas are present their perfusion must be reduced so that they contribute relatively little to the arterial desaturation. In this connexion it should be stressed that our study does not contain any data from the immediate post-operative period. The finding that hypoxaemia during the first hours after operation can be abolished by a few deep respirations (Bendixen et al., 1963) seems to indicate that atelectases in this period are of greater significance.

The identical results obtained in clinically complicated and uncomplicated cases are in agreement with the findings of Palmer, Gardiner, and McGregor (1965). This indicates that it is the surgical intervention itself which gives rise to the ventilation/perfusion disturbances and to the development of atelectatic areas. Other factors, such as pre-existing lung disease, bronchitis, or airway infections, determine whether clinically manifest complications do in fact develop.

\section{REFERENCES}

Anscombe, A. R. (1957). Pulmonary Complications of Abdominal Surgery. Lloyd-Luke, London.

Bartels, H. (1951). Potentiometrische Bestimmung des Sauerstoffdruckes im Vollblut mit der Quecksilbertropfelektrode. Pflügers Arch. ges. Physiol., 254, 107.

Beecher, H. K. (1933). Effect of laparotomy on lung volume. Demonstration of a new type of pulmonary collapse. J. clin. Invest., 12, 651 . 
Bendixen, H. H., Hedley-Whyte, J., and Laver, M. B. (1963). Impaired oxygenation in surgical patients during general anesthesia with controlled ventilation; a concept of atelectasis. New Engl. J. Med., 269, 991.

Brattström, S. (1954). Postoperative pulmonary ventilation with reference to postoperative pulmonary complications. Acta chir. scand., Suppl. 195.

Carlsten, A., Norlander, O., and Troell, L. (1954). Observations on the postoperative circulation. Surg. Gynec. Obstet., 99, 227.

Conway, C. M., and Payne, J. P. (1963). Post-operative hypoxaemia and oxygen therapy. Brit. med. J., 1, 844.

(1964). Hypoxaemia associated with anaesthesia and controlled respiration. Lancet, 1,12 .

Gordh, T., Linderholm, H., and Norlander, O. (1958). Pulmonary function in relation to anesthesia and surgery evaluated by analysis of oxygen tension of arterial blood. Acta anaesth. scand., 2,15 .

Lassen, N. A., Mellemgaard, K., and Georg, J. (1961). Tritium used for estimation of right-to-left shunts. J. appl. Physiol., 16, 321.

Linderholm, H., and Norlander, O. (1958). Carbon dioxide tension and bicarbonate content of arterial blood in relation to anesthesia and surgery. Acta anaesth. scand., $2,1$.

Mellemgaard, K. (1966). The alveolar-arterial oxygen difference: its size and components in normal man. Acta physiol. scand., 67, 10.

_Lassen, N. A., and Georg, J. (1962). Right-to-left shunt in normal man determined by the use 'of tritium and krypton 85 . J. appl. Physiol., 17, 778 .
Nunn, J. F., and Payne, J. P. (1962). Hypoxaemia after general anaesthesia. Lancet, 2,631 .

Palmer, K. N. V., and Gardiner, A. J. S. (1964). Effect of partial gastrectomy on pulmonary physiology. Brit. med. J., 1, 347. gastrectomy. Thorax, 20,73. lsen, E. F. (1965). Postoperativ hypoksæmi behandlet med ilt gennem næsekateter. Ugeskr. Lag., 127, 1609.

Robinson, C. V. (1955). Improved methane proportional counting method for tritium assay. Nucleonics, 13, no. 11 (Nov.), p. 90.

Ross, J. C., Eller, J. L., Ley, G. D., and King, R. D. (1963). Alterations in lung volume and intrapulmonary gas mixing after inguinal herniorrhaphy in patients with normal lung function and in patients with emphysema. Amer. Rev. resp. Dis., 88, 213.

Sendroy, J. Dillon, R. T., and Van Slyke, D. D. (1934). Studies of gas and electrolyte equilibria in blood. XIX. The solubility and physical state of uncombined oxygen in blood. J. biol. Chem., $105,597$.

Severinghaus, J. W. (1958). Oxyhemoglobin dissociation curve correction for temperature and $\mathrm{pH}$ variation in human blood. $J$. appl. Physiol., 12, 485.

Siggaard Andersen, O., Engel, K., Jørgensen, K., and Astrup, P. (1960). A micro method for determination of pH, carbon dioxide tension, base excess and standard bicarbonate in capillary blood. Scand. J. clin. Lab. Invest., 12, 172.

Troell, L. (1951). Post-operative changes in circulation and the effects of oxygen therapy. Acta chir. scand., 102, 203. 